\title{
IMPLEMENTAÇÃO DA POLÍTICA DO AMBIENTE EM CABO VERDE: O CASO DO PARQUE NATURAL DE SERRA DA MALAGUETA
}

\author{
IMPLEMENTATION OF THE ENVIRONMENT POLICY IN CAPE \\ VERDE: THE CASE OF SERRA DA MALAGUETA NATURAL PARK
}

\section{Manuel Leão Silva de Carvalho}

Doutorando em Gestão e Políticas Ambientais e Mestre em Gestão e Auditoria Ambiental. Técnico Sénior da Direção Nacional do Ambiente da República de Cabo Verde. E-mail: leaocarvalho21@yahoo.com. br /

manuel.carvalho@student.u nicv.edu.cv

\section{RESUMO}

Com o presente artigo procura-se demonstrar como é que a aplicação da política do ambiente à gestão de áreas protegidas pode aumentar a sua eficácia de gestão. A metodologia utilizada foi a revisão da literatura, consulta ao plano de gestão do Parque Natural de Serra da Malagueta, aos relatórios das atividades realizadas nessa área protegida, bem como à legislação nacional aplicável. A direção e a equipa técnica do Parque e as comunidades locais foram igualmente consultadas, tendo em vista a avaliação da perceção que têm sobre a eficácia de gestão dessa importante área protegida. Em termos de resultados alcançados, constata-se que a eficácia de gestão em 2007 foi Pouco Satisfatória, enquanto a avaliação de 2016 foi Medianamente Satisfatória. Esta diferença justifica-se, pois: (i) em 2007, embora tivesse havido alguma atividade de gestão, o Parque encontrava-se em processo de elaboração do plano de gestão, processo esse que culminou com a aprovação do plano em 2008 e o início da sua implementação no mesmo ano; (ii) a política de gestão proativa que o Parque conheceu com a implementação do plano de gestão a partir de 2008, facilitada pela co-governança, de natureza colaborativa, adotada. Este trabalho permitiu perceber como é que o processo participativo utilizado na territorialização de políticas públicas de gestão ambiental pode contribuir para a sustentabilidade de espaços naturais protegidos.

Palavras-chave: Recursos naturais; Política ambiental; Ambiente; Gestão ambiental; Gestão de áreas protegidas

\section{ABSTRACT}

This paper aims to demonstrate how the application of environmental policy to the management protected areas can improve their management effectiveness. The methodology used in this paper was to review the literature, consulting the management plan of the Serra da Malagueta Natural Park and the reports of the activities carried out in that protected area. The Park's management and technical team and local communities were also consulted, in order to assessing their perception of the management effectiveness of this important protected area. In terms of results achieved, it appears that the management effectiveness in 2016 was Moderately Satisfactory, while the 2007 evaluation was Unsatisfactory. This difference is justified: (i) in 2007, although there had been some management activity, the Park was in the process of preparing the management plan, which culminated in the approval of the plan in 2008 and the beginning of its implementation in the same year; (ii) the proactive management policy that the Park became aware of with the implementation of the management plan since 2008, facilitated by co-governance, collaborative nature, adopted. This paper allowed us to understand how the participatory process used in the territorialization of public environmental management policies can contribute to the sustainability of protected natural spaces.

Keywords: Natural resources; Environmental policy; Environment; Environmental management; Management protected areas 


\section{INTRODUÇÃO}

A partir dos meados do século XIX, o crescimento exponencial da população mundial tem constituído preocupações das autoridades nacionais e internacionais, no concernente, não só à segurança alimentar, mas também à satisfação de outras necessidades, uma vez que o modelo de desenvolvimento económico estabelecido não tem assegurado a repartição justa e equitativa do rendimento, o que tem provocado pressões e ameaças crescentes sobre os recursos naturais e ambientais, com consequências incalculáveis.

Por outro lado, o uso indiscriminado dos recursos energéticos de origem fóssil, para alimentar o referido modelo, tem agravado o aquecimento global, devido à emissão de gases com efeito de estufa, com algumas consequências evidentes, particularmente ao nível da degradação dos ecossistemas, tanto terrestres como marinhos, com subsequentes perdas da biodiversidade, e não só!

Contudo, no mundo inteiro tudo se passava, aparentemente, despercebido, até que em 2005, o furacão Katrine atinge Nova Orleans, destruindo tudo no seu caminho, altura em que a América de repente percebe que as mudanças climáticas não eram ilusões:

Era uma catástrofe com consequências dramáticas que mata em grande escala: cheias em Moçambique em 2000, vagas de calor na Europa em 2003, seca extrema na Austrália em 2006, furacões uns atrás outros nas Caraíbas, os sinais de aviso multiplicam-se. Perante a magnitude dos danos, o Júri do Premio Nobel da Paz envia uma mensagem forte em 2007: Concedeu o premio aqueles que lutam para conseguir a nossa atenção (Ascensão da Ecológica, 2009) ${ }^{1}$.

A maior parte dos problemas ambientais existentes no mundo devem-se, sobretudo, a políticas ambientais desajustadas a contextos ecológicos e socioeconómicos e culturais, caraterizadas, principalmente, por medidas de política de natureza passiva ou reativa, ao invés de proativa, na perspetiva de antecipação dos problemas.

$\mathrm{O}$ entendimento que se tem da natureza e a forma pela qual agricultores, industriais, trabalhadores e consumidores, enfim a sociedade, de um modo geral, se relaciona com ela e considera ou interpreta qualquer tipo de ação impactante decorrente de suas atividades, dependem em grande medida desse entendimento inicial. É, pois, importante entender e diferenciar, do ponto de vista teórico, os conceitos de natureza, ambiente, meio ambiente, recursos ambientais e recursos naturais, no sentido de se promover o seu esclarecimento, ou senão, pelo menos, o seu debate.

\footnotetext{
${ }^{1}$ Ascensão Ecológica (2009). Disponível em: https://www.youtube.com.
} 
Cabo Verde, enquanto país pequeno, insular e arquipelágico, desde a sua independência, viu-se obrigado a adotar estratégias que permitissem, por um lado, criar condições legais para enfrentar os problemas ambientais, e por outro, implementar um conjunto de medidas concretas que assegurassem a prevenção, correção ou compensação de potenciais impactes negativos no território, seja de natureza ecológica, económica ou sociocultural.

É com esta preocupação que os sucessivos governos de Cabo Verde têm envidado esforços na definição e implementação de políticas ambientais que garantam, por um lado, a preservação e conservação do ambiente e, por outro, a gestão dos recursos ambientais estribados em princípios de desenvolvimento sustentável.

O objetivo deste trabalho é demonstrar como é que a aplicação da política do ambiente aos espaços naturais protegidos pode contribuir para aumentar a sua performance em termos de eficácia de gestão.

\section{Enquadramento teórico}

Em termos históricos, o estudo das políticas públicas sempre esteve associado à Ciência Política e à Administração. No concernente à Ciência Política, ela, em regra, está associada a três abordagens: (i) o questionamento clássico da ciência política quanto à legitimidade do sistema político vigente e à capacidade do Estado em garantir e proteger a felicidade do cidadão, em particular, ou da sociedade como um todo; (ii) a análise das forças políticas cruciais no processo de tomada de decisão; e (iii) dedicada ao estudo dos resultados que determinado sistema político vem produzindo por meio da especificidade de suas políticas públicas de cunho financeiro, económico, tecnológico, social ou ambiental.

Relativamente à Administração, a avaliação das ações governamentais tem sido um dos principais alvos, e isto não só com vista à perceção da eficácia e ou eficiência dos processos de gestão da coisa pública, mas, também, do processo de aprendizagem institucional o que contribuiria para a verificação de ganhos das ações governamentais, no quesito satisfação dos usuários e legitimidade sociopolítica.

As políticas públicas devem, necessariamente, contemplar um determinado fim ou uma área específica da realidade quotidiana, pois trata-se de intervenções do Estado, em conjunto ou não com a sociedade civil (ONG, grupos empresariais, comunidades, entidades internacionais, entre outras).

Entretanto, segundo Salheb e al. (sd), dada a expansão económico-industrial internacional e os efeitos nocivos da intervenção humana na natureza (aquecimento global, 
desertificação, desflorestação, extinção de espécies, derretimento das calotas polares, contaminação de fontes d'água, chuvas ácidas, destruição de recursos naturais, caça e pesca predatórias, entre outros), tais políticas por terem papel tão incisivo e decisivo no modo de vida e nos modos de produção, passam a ter um papel fundamental como instrumentos não só de desenvolvimento económico-social, mas também, como forma de garantia de preservação de recursos às futuras gerações.

Assim, para a mesma fonte, "as políticas públicas ambientais assumiram um papel essencial de preservação, conservação e proteção do meio ambiente, integrando sua proteção aos demais objetivos da vida em sociedade, como forma, inclusive, de proporcionar qualidade de vida" (p. 12).

Segundo MILARÉ, 2007, p. 285), citado por Salheb e al. (sd, p. 15),

Ao se falar de políticas públicas ambientais, deve-se ter em mente que estas, sob pena de ineficácia, 'não podem ser desconexas ou descoordenadas'. Deve haver, então, complementaridade entre as ações e objetivos, caso contrário perder-se-ão no vazio da inépcia posto que a própria vida, em todas as suas formas, é a destinatária destas ações e objetivos.

Segundo Ferreira (2008), política ambiental é o conjunto de metas e instrumentos que têm por objetivo mitigar os potenciais impactos negativos no ambiente provocados pela ação antrópica, prevendo penalidades pelo não cumprimento das medidas estabelecidas. A política ambiental pode influenciar as atividades dos diversos agentes económicos, nomeadamente a indústria e o comércio.

O mesmo autor diz que a política ambiental é, em regra, a nível mundial, sistematizada a partir de três etapas:

A primeira etapa corresponde ao período que vai do final do século XIX até meados do século XX, quando as externalidades económicas do crescimento passaram a se impôr, exigindo a intervenção estatal para o combate à degradação ambiental. Durante essa etapa, a política ambiental era assegurada via tribunais, onde os poluidores e as vítimas de poluição se embatiam.

A segunda etapa acontece a partir dos anos 50, quando houve um aumento do crescimento económico e consequentemente, o aumento da degradação ambiental. Tal etapa foi caraterizada pela premissa apelidada de Comando-Controlo, que como o próprio nome sugere, estabeleceu normas e metas a serem atingidas e cumpridas. A política de Comando-Controlo apresenta duas direções oblíquas: (i) estabelece padrões de emissões incidentes através da autoridade ambiental; (ii) determina o uso de tecnologias limpas com o intuito de combater a poluição e cumprir os padrões de emissão incidentes. 
Apesar de compreensível em matéria de medidas de políticas, a política de ComandoControlo também acusou deficiências, porquanto a sua implementação foi excessivamente morosa, agravada por contestações judiciais e a utilização de tecnologias limpas não foram consequentes.

A terceira e última etapa corresponde à atual, a qual os autores chamam de política "mista" de Comando-Controlo. É mista, pois além de utilizar os padrões de emissão incidentes como instrumentos, passam a ser utilizados os padrões de qualidade ambiental e instrumentos económicos (Ferreira, 2008).

Ainda, para Ferreira (2008), pode-se, de um modo geral, dizer que são três os instrumentos utilizados pela política ambiental: Comando-Controlo, económico e comunicação.

O instrumento Comando-Controlo, institui normas, regras e procedimentos de produção e utilização dos recursos, incorrendo-se em penalidades o incumprimento de tais medidas; o instrumento económico verifica-se mediante cobrança de tarifas e taxas sob a utilização dos recursos, onde esse capital será revertido em prol dos órgãos ambientais, assim como poderá subsidiar a implantação de tecnologias limpas nas empresas. Pode ser feito também a redução fiscal de empresas comprometidas com o cuidado com o meio ambiente; e, finalmente, o instrumento comunicação poderá ser utilizado na divulgação de informações, promoção de educação ambiental, mediação de encontros de agentes económicos e divulgação de selos ambientais.

É nosso entendimento que a comunicação é um elemento estratégico na materialização da política ambiental, pois como diz MONTESQUIEU (1748), citado por Oosterbeek (2013),

Quando se quer mudar os costumes e as maneiras, não se deve mudá-los pelas leis; isso pareceria demasiado tirânico: é melhor mudá-los com outros costumes e outras maneiras (...); e é uma política muito má mudar pelas leis o que deve ser mudado pelas maneiras.

As áreas protegidas têm sido, estratégicamente, escolhidas como espaços para territorialização de poíticas ambientais, não só em termos de medidas de mitigação e ou adaptação dos efeitos das mudanças climáticas, conservando e protegendo os recursos biológicos, geológicos, mas também como palcos de transformação socioeconómicas e culturais.

As áreas protegidas surgiram desde a criação, em 1872, do primeiro parque nacional do mundo (Yellowstone National Park), nos Estados Unidos, data a partir da qual o conceito e a forma de aplicar os princípios de conservação sofreram várias mudanças. O termo "Parque" foi 
entendido inicialmente como uma área de proteção para o lazer da população, ao passo que o termo "nacional" concedia uma conotação mais precisa à uma superfície de propriedade de uma nação, sendo administrada por seu respetivo governo. Moscovici (1974), citado por Diegues (1998).

Entretanto, segundo Spínola (2013), a necessidade e o desejo de preservação fa natureza foram manifestadas por diversas sociedades humanas, muito mais cedo do que geralmente se imagina. "Atribui-se a Platão, por exemplo, ainda no século IV a.C., a preocupação com a preservação das florestas, em função do seu papel predominante como reguladoras do ciclo da água e controladoras da erosão" (pp. 72-73).

Igualmente, segundo Matias (2009, p. 2), o movimento de criação de áreas protegidas é muito anterior ao movimento ambientalista e aos acordos internacionais ligadas à conservação da diversidade biológica, já que as suas raízes remontam ao século XVIII: "essas raízes não são mais que as ideias precursoras das teorias conservacionistas e preservacionistas que surgiram nos Estados Unidos da América no século XIX e que ainda hoje influenciam as políticas ambientais e de conservação da natureza".

Para esse autor,

As obras de George Perkins Marsh, Ralph Waldo Emerson e Henry David Thoreau, influenciados, por sua vez, pelo romantismo europeu do final do século XVIII e início do século XIX, exaltavam a necessidade de proteger a natureza da ignorância e presunção do homem, tendo constituído uma forte inspiração para o movimento de criação de áreas protegidas. (p. 2).

Uma área protegida é um espaço geográfico, claramente definido, reconhecido, consagrado e gerido, através de meios legais ou outros meios efectivos, de modo a alcançar a conservação, a longo prazo, da natureza e dos serviços ecológicos e valores culturais associados (Dudley, 2008). As áreas protegidas são criadas para preservar valores específicos, como biológicos, socioeconómicos e culturais. A compreensão desses valores é fundamental para a gestão de uma área protegida.

Segundo Diegues (1998), os espaços naturais protegidos conheceram evolução quanto a paradigmas de conservação, desde a ideia de um espaço para proteção da natureza afastada do homem, através do estabelecimento de "ilhas", para que o homem moderno pudesse admirála e reverenciá-la.

Esses lugares paradisíacos serviriam também como locais selvagens, onde o homem pudesse refazer as energias gastas na vida estressante das cidades e no trabalho monótono, até a inclusão das populações na exploração dessas áreas protegidas, já alinhado com a sustentabilidade de CARLOWITZ (1713), citado por Floriano (2007), que diz que "A natureza 
deve ser obrigatoriamente utilizada com base nas suas características naturais para o bem-estar da população, gerida e conservada com cuidado e com a responsabilidade de deixar um bom legado para as futuras gerações" (p. 105).

Segundo ART (1998), citado por Dulley (2004, p. 18), Ambiente é o “... conjunto de condições que envolvem e sustentam os seres vivos na biosfera, como um todo ou parte desta, abrangendo elementos do clima, solo, água e de organismos". Já para o mesmo autor, Meio ambiente a "soma total das condições externas circundantes no interior das quais um organismo, uma condição, uma comunidade ou um objeto existe" (p. 18). Neste sentido, Santos (1996), citado por Dulley (2004, p. 18) discutindo o conceito de sustentabilidade, entende que o ambiente compreende a base física e material da vida, a infraestrutura que possibilita a sua existência em toda a sua plenitude.

Meyer-Abich (1993), citado por Dulley (2004, p. 19), quando se refere ao que denomina de "mundo conatural", ou seja, "cada espécie depende de um determinado número de elementos específicos da natureza, que no seu conjunto são indispensáveis à sobrevivência de cada uma", veio mostrar claramente o direito de preservação do meio ambiente específico de cada espécie. E, além disso, não cai no antropocentrismo caraterístico da maioria das políticas ambientais contemporâneas, que apenas se preocupam com os elementos do ambiente necessários à sobrevivência da espécie humana, ou seja, ao seu meio ambiente.

Assim, na perspectiva Dulley (2004, p. 19), para cada espécie existiriam grupos variados de elementos inter-relacionados, imprescindíveis à sobrevivência dessa espécie, constituindose em meios ambientes específicos. Se se admitir que a natureza é pensada, culturalmente, única e exclusivamente pelo homem, reforça-se a ideia de que ao se referir ao ambiente, está-se a falar de "conjunto dos meios ambientes de todas as espécies, pensados e/ou conhecidos pelo sistema social humano" (p. 20).

Para Dulley (2004), o entendimento que se tem da natureza e a forma pela qual a sociedade, de modo geral, se relaciona com ela e considera ou encara qualquer tipo de ação impactante decorrente de suas atividades, dependem em grande medida desse entendimento inicial da natureza.

Com base no conceito de sustentabilidade de CARLOWITZ (1713), a gestão ambiental pode ser definida como a administração dos recursos ambientais com o objetivo de conserválos e garantir que as gerações futuras encontrem um ambiente compatível com as suas necessidades.

Segundo Floriano (2007, p. 1)), as políticas de gestão ambiental podem ser caraterizadas segundo o seu caráter e nível de abrangência. “Quanto ao caráter, podem ser classificadas como 
público e privado. Quanto à abrangência, podem ser políticas internacionais, federais, estaduais ou municipais, entre outros."

Para IBAMA (1995), citado por Floriano (2007, p.2),

Gestão ambiental pública é um processo de mediação de interesses e conflitos entre atores sociais que agem sobre os meios físico-natural e construído. Este processo de mediação define e redefine, continuamente, o modo como os diferentes atores sociais, através de suas práticas, alteram a qualidade do meio ambiente e também, como se distribuem na sociedade os custos e os benefícios decorrentes da ação destes agentes.

Com base nesta definição, depreende-se que as políticas públicas de gestão ambiental têm como objetivo, tanto a gestão de recursos para a proteção do ambiente - visto o ambiente como a natureza apenas pensada pelo homem -, como servir de orientação na solução de potenciais conflitos sociais que envolvam questões de natureza ambiental, com vista ao bemestar social e a conservação de recursos ambientais para as gerações vindouras.

Segundo Floriano (2007, pp. 2-3), política ambiental privada "pode ser entendida como a declaração de uma organização, expondo suas intenções e princípios em relação ao seu desempenho ambiental global, que provê uma estrutura para ação e definição de seus objetivos e metas ambientais."

Para esse autor, a gestão ambiental privada integra o sistema de gestão global de uma organização e trata-se de um processo administrativo, dinâmico e interativo de recursos, que tem por objetivo:

equilibrar a proteção ambiental e a prevenção de poluição com as necessidades socioeconômicas e ajudar a proteger a saúde humana, através da formulação de uma política e objetivos que levem em conta os requisitos legais e as informações referentes aos impactos ambientais significativos, visando a melhoria contínua no desempenho ambiental da organização de forma a atender às necessidades de um vasto conjunto de partes interessadas e às crescentes necessidades da sociedade sobre proteção ambiental (p. 3).

Em termos territoriais, é possível classificar as políticas de gestão ambiental "como rurais e urbanas no nível global, nacional, de grandes regiões nacionais, estadual, municipal e, mais recentemente, em nível de regiões dos Estados, de bacias hidrográficas e de ecorregiões (ecossistemas)" (Floriano, 2007, p. 3).

Em termos de abordagm de gestão ambiental nas organizações, ela pode ser de natureza passiva, reativa ou proativa. Passiva, não se faz nada, utilizando a estratégia de diluir e dispersar o poluente, usando a capacidade auto-depuradora do meio; reativa, utiliza-se a tecnologia de fim-de-linha para redução das descargas poluentes; e proativa, tem que ver com a redução do consumo de matérias primas e uso mais eficiente dos recursos naturais e energia. 
Em matéria de gestão de áreas protegidas, a classificação de uma área sob uma categoria de proteção, seja esta de Parque, Reserva ou outra qualquer prevista na lei, não é suficiente para garantir o cumprimento dos objetivos definidos, aquando da sua classificação. É necessário, pois, dotar os órgãos responsáveis pela sua gestão de recursos económicos, administrativos, humanos e materiais para que esses objetivos sejam cumpridos.

Segundo Matias (2009), tendo em conta que os objetivos de uma área protegida variam com a categoria da área, "a gestão dos espaços protegidos apresenta variações que vão desde uma gestão dita ativa a uma gestão básica que, geralmente, inclui apenas ações no âmbito do controlo administrativo e da vigilância" (p. 11).

Da vigilância consta o conjunto de atividades levadas a cabo tendo em vista a identificação e prevenção atividades não autorizadas ou prejudiciais para a conservação da natureza e, o controlo administrativo tem que ver sobretudo com atribuição de autorizações, concessões, subsídios, compensações ou pareceres.

Para a mesma fonte, a gestão ativa refere-se a todas as medidas que visam à preservação do património natural, incluindo "a prevenção de incêndios, o restauro de habitats e zonas degradadas, acções de erradicação de espécies invasoras e reintrodução de espécies, implementação de planos de conservação de espécies e controlo das populações” (p. 11).

Após a criacão oficial de uma área protegida, a sua gestão conhecerá diferentes fases, porquanto os recursos humanos e financeiros de que dispõe para a sua operacionalização vão acusando melhorias, em termos de aumento e consolidação. Assim,

Nas fases iniciais de desenvolvimento, de um modo geral, predominam as ações de
vigilância e controlo administrativo às quais se seguem as de divulgação e uso
público. Geralmente, só nas fases de consolidação e gestão activa das áreas protegidas
se desenvolvem ações de conservação de espécies e habitats, de promoção do
desenvolvimento socioeconómico, de educação, investigação, entre outras (Matias.
2009, p.12).

\section{METODOLOGIA}

Para o presente estudo foi utilizada uma Área Protegida (Parque Natural de Serra da Malagueta), gerida pela Direção Nacional do Ambiente (DNA), do Ministério da Agricultura e Ambiente, com a categoria de Parque Natural, com um total de 774 hectares. Essa área encontrase localizada na ilha de Santiago, uma das 9 ilhas habitadas de Cabo Verde, entre as coordenadas geográficas $15^{\circ} 10^{\prime} 12^{\prime \prime}$ e $15^{\circ} 12^{\prime} 12^{\prime \prime}$ de latitude Norte e $23^{\circ} 39^{\prime} 26^{\prime \prime}$ e $23^{\circ} 42^{\prime} 17^{\prime \prime}$ de longitude oeste do meridiano de Greenwich. No Quadro 1, apresentam-se a superfície, a localização geográfica e os municípios abrangidos pela área protegida estudada. 
Quadro 1 - Superfície, localização geográfica e municípios abrangidos pelo Parque Natural

\begin{tabular}{|c|c|c|c|c|}
\hline Nome & $\begin{array}{l}\text { Superfície } \\
\text { (Ha) }\end{array}$ & Latitude & Longitude & $\begin{array}{l}\text { Municípios } \\
\text { abrangidos }\end{array}$ \\
\hline $\begin{array}{l}\text { Parque Natural de Serra } \\
\text { da Malagueta }\end{array}$ & 774,00 & $\begin{array}{l}15^{\circ} 10^{\prime} 12^{\prime \prime} \text { e } 15^{\circ} \\
12^{\prime} 12^{\prime} \mathrm{N}\end{array}$ & $\begin{array}{l}23^{\circ} 39^{\prime} 26^{\prime \prime} \text { e } 23^{\circ} \\
42^{\prime} 17^{\prime \prime} \mathrm{O}\end{array}$ & $\begin{array}{l}\text { Santa Catarina, } \\
\text { Tarrafal e S. Miguel }\end{array}$ \\
\hline
\end{tabular}

Fonte: Construção própria

Este estudo é de natureza quantitativa, complementado com o método qualitativo. No que concerne aos objetivos da pesquisa, ela é descritiva e explicativa; quanto ao objeto, tratase de um estudo de caso.

Em termos de técnica de coleta de dados, utilizaram-se a pesquisa bibliográfica, documental, entrevista não-diretiva e observação participante. Trata-se de técnicas importantes e precisas, porquanto permitem recorrer a informações primárias e secundárias, tendo em vista a obtenção de mais conhecimentos acerca do objeto em estudo.

O Órgão Gestor do Parque e as comunidades locais foram igualmente consultadas, tendo em vista a avaliação da perceção que têm sobre os impactos socioeconómicos e ecológicos dessa importante área protegida.

Relativamente ao tratamento de dados, o método Management Efectiveness Tracking Tool foi utilizada na avaliação da eficácia de gestão, comparando a eficácia de 2007 com a de 2016.

\section{MODELO DE GESTÃo DO PARQUE NATURAL DE SERRA DA MALAGUETA}

Em Cabo Vede, o departamento governamental responsável pelo ambiente é o Ministério da Agricultura e Ambiente (MAA) a quem compete a conceção, coordenação, controlo, execução e avaliação das políticas definidas pelo Governo em matéria de ambiente, em particular no domínio dos recursos naturais e da conservação da natureza.

O MAA integra, por sua vez, o Conselho Nacional do Ambiente, órgão de natureza consultiva e deliberativa, sobre as grandes opções da política e de cooperação entre as entidades e organizações públicas e privadas que intervenham nos domínios do ambiente e respetiva relação com a política nacional de desenvolvimento.

O Ministério compreende ainda a Direção Nacional do Ambiente, com a missão de (i) proteger espécies ameaçadas, especialmente as endémicas, os habitats e ecossistemas frágeis, de forma a preservar os recursos naturais; (ii) adotar medidas que visem a proteção dos ecossistemas terrestres e aquáticos ameaçados de destruição; (iii) preparar e executar a estratégia nacional de proteção e conservação da natureza (Decreto-Lei n. ${ }^{\circ} 49$ (2016, 27 de Setembro).

De acordo com o mesmo Decreto, da estrutura da Direção Nacional do Ambiente, consta 
uma Direção de Serviços de Conservação da Natureza, com a missão específica de: (i) propor a criação de áreas protegidas e garantir a sua implementação e gestão; (ii) promover o estudo e o conhecimento dos valores das áreas protegidas, assim como a elaboração dos planos de ordenamento e gestão, dos quais constarão o zonamento e os usos dessas áreas; (iii) promover, elaborar e implementar estratégias e planos de conservação de espécies e ecossistemas, em particular as espécies protegidas, endémicas e em perigo de extinção, e ecossistemas sensíveis.

Ao nível das ilhas, existem, exceto a ilha Brava, Unidades de Gestão de Área Protegida (UGAP), sob a coordenação das Delegações do Ministério da Agricultura e Ambiente, que são responsáveis pela implementação das atividades de gestão de áreas protegidas. A UGAP é assessorada por um Conselho Assessor de Áreas Protegidas que garante a participação da população local e a cooperação dos vários órgãos da administração, no processo de gestão de área protegida.

Esse Conselho Assessor foi criado de acordo com o (MAA, 2003), que diz, no seu artigo $22^{\circ}$, que o departamento governamental responsável pela área do ambiente pode criar um Conselho Assessor para cada ilha ou, excecionalmente para uma área protegida, com objetivo de facilitar a gestão, através da participação da população e cooperação dos vários órgãos da administração (p. 22).

Esse mesmo artigo, no ponto 2., diz que "o Conselho Assessor é um órgão de colaboração vinculado administrativamente ao departamento governamental responsável pela área do ambiente, que serve de espaço de debate, e atua apenas com funções de assessoria".

O Conselho Assessor, de acordo com a mesma fonte, é composto, pelo menos, por um representante do departamento governamental responsável pela área do ambiente na ilha, pelo diretor da área protegida, um representante dos serviços desconcentrado do Estado na ilha, um representante da comunidade local, um representante da Câmara Municipal e um representante das associações ligadas ao ambiente.

Além dessas disposições legais que facilitam a participação das instituições e comunidades locais no processo de gestão de uma área protegida, uma outra medida importante constante do artigo $23^{\circ}$ do referido decreto, tem que ver com o Convénios de Gestão Concertada, que podem ser estabelecidos para gestão parcial ou total de algumas áreas protegidas, “com entidades locais, associações comunitárias e organizações nãogovernamentais, interessadas em matéria do ambiente, entidades internacionais ou programas de cooperação bilateral ou multilateral” (p. 23).

Em Cabo Verde existe um único modelo de gestão para todas as áreas protegidas, como acontece, aliás, em Portugal e Espanha. Entretanto, em França, Itália e Reino Unido, criaram- 
se diferentes modelos de gestão de acordo com a categoria de área protegida. De notar, por outro lado, que “em França e Itália, particularmente, mas também no Reino Unido, foram adotados modelos que promovem a gestão descentralizada das áreas protegidas, nomeadamente através da criação de organismos autónomos” (Matias, 2009, p. 110).

Não existindo, em Cabo Verde, um modelo de gestão descentralizada, como organismos autónomos, embora a legislação o preveja, a participação ativa na gestão das áreas protegidas, por parte das comunidades locais, é assegurada através da criação de órgãos consultivos em que estão devidamente representados os vários interesses.

\section{RESULTADOS E DISCUSSÃO}

Da análise do modelo de gestão do Parque, que também se aplica no âmbito nacional, depreende-se que existem três tipos de órgãos de acordo com seu papel na gestão das áreas protegidas: (i) Órgão executivo, responsável pela elaboração e implementação dos planos de ordenamento e ou gestão das áreas protegidas; (ii) Órgão consultivo, que exerce apenas uma função consultiva, não lhe sendo facultado poder de decisão ou de execução de medidas de gestão. Pode ter um carácter científico, não representando neste caso nenhum interesse específico, ou abranger vários sectores da sociedade e neste caso os membros representam normalmente os interesses de algum sector e da comunidade; e (iii) Órgão de participação social, que exerce essencialmente uma função consultiva mas também de execução em determinadas matérias da gestão.

No âmbito local, o Parque é gerido por um Diretor, coadjuvado por uma equipa técnica e assessorado por um Conselho Assessor de áreas protegidas. Desde a criação do Conselho Assessor de PNSM em 2006, várias reuniões e decisões foram tomadas, em prol de uma gestão eficiente e eficaz desse importante espaço natural protegido, numa perspetiva de um desenvolvimento que se deseje sustentável, do ponto de vista ecológico, socioeconómico e cultural.

O zonamento do Parque, no âmbito do processo de planeamento, permite a conciliação de atividades de conservação com as de exploração dos recursos pelas comunidades, que vivem dentro e ou na zona de amortecimento, para além delas, também, poderem participar, tanto no processo de elaboração dos instrumentos de gestão, como sua implementação.

O funcionamento do Parque e as abordagens utilizadas nas decisões tomadas pelo Órgão Gestor nas suas reuniões periódicas, com participação da equipa técnica e do Conselho Assessor, leva-nos a classificar a governança do Parque como "Co-Governança", de natureza 
"Colaborativa".

A materialização de políticas de gestão ambiental em Cabo Verde tem acontecido, a nível de gestão da Rede Nacional de Áreas Protegidas, por meio de elaboração e implementação de instrumentos de gestão de natureza especial, como sejam os planos de ordenamento e gestão de áreas protegidas, planos de ecoturismo, entre outros.

A elaboração e implementação do Plano de Gestão do Parque Natural de Serra Malagueta inserem-se no âmbito das exigências constantes do artigo $16^{\circ}$ do (MAA, 2003), que diz expressamente “ 1 . Os objetivos de conservação previstos no presente diploma podem ser materializados através de um plano de gestão das áreas protegidas onde se percebe tal necessidade e, em qualquer caso, nos Parques Naturais" (p. 17).

O supracitado plano procura territorializar a política e gestão ambiental a dois níveis: (i) através da normativa, que estabelece a "matriz de compatibilidade de usos", classificados em C: Compatível; NC: Não Compatível; CL: Compatível com Limitações; NP: Não Procede; e (ii) através de ordenamento, com recurso ao processo de zonamento territorial. Ver Quadro 2.

Quadro 2- Compatibilidade e Regulação de Usos Específicos

\begin{tabular}{|c|c|c|c|c|c|c|c|}
\hline \multicolumn{8}{|c|}{$\begin{array}{c}\text { COMPATIBILIDADE ENTRE USOS ESPECÍFICOS PRIVADOS E } \\
\text { ZONAS ESPECÍFICAS }\end{array}$} \\
\hline USOS E ACTIVIDADES PRIVADAS & Z.1 & $\mathrm{Z} .2$ & Z.3 & Z.4 & Z.5 & Z.6 & $\mathrm{Z} .7$ \\
\hline Residencial-vivenda unifamiliar & NP & $\mathrm{NC}$ & NP & $\mathrm{NC}$ & $\mathrm{NC}$ & $\mathrm{CL}^{*}$ & $\mathrm{CL}^{*}$ \\
\hline Agrícola de sequeiro & NP & CL* & $\mathrm{NC}$ & $\mathrm{NC}$ & $\mathrm{C}$ & $\mathrm{C}$ & $\mathrm{C}$ \\
\hline Pecuária estabulada & NP & $\mathrm{NC}$ & $\mathrm{NC}$ & $\mathrm{NC}$ & $\mathrm{CL}$ & CL & $\mathrm{CL}$ \\
\hline Pastoreio livre & $\mathrm{NP}$ & $\mathrm{NC}$ & $\mathrm{NC}$ & $\mathrm{NC}$ & $\mathrm{C}$ & $\mathrm{NC}$ & $\mathrm{NC}$ \\
\hline Exploração produtiva florestal & $\mathrm{NC}$ & CL* & $\mathrm{NC}$ & CL* & CL* & CL* & $\mathrm{CL}^{*}$ \\
\hline Colecta de espécies naturais & $\mathrm{NC}$ & NC & $\mathrm{NC}$ & $\mathrm{NC}$ & CL* & CL* & CL* \\
\hline Recolha de pasto & $\mathrm{NP}$ & CL* & $\mathrm{NC}$ & $\mathrm{CL}^{*}$ & $\mathrm{C}$ & NP & NP \\
\hline Utilização de nascentes naturais de água & $\mathrm{CL}$ & NP & $\mathrm{NP}$ & $\mathrm{C}$ & $\mathrm{C}$ & $\mathrm{C}$ & $\mathrm{C}$ \\
\hline Cinegético - recreativo & $\mathrm{NC}$ & NC & $\mathrm{NC}$ & CL* & CL* & NP & NP \\
\hline Extracção de inertes & $\mathrm{NC}$ & $\mathrm{NC}$ & $\mathrm{NC}$ & $\mathrm{NC}$ & $\mathrm{NC}$ & $\mathrm{NC}$ & $\mathrm{NC}$ \\
\hline Educativo & NP & $\mathrm{CL}$ & $\mathrm{CL}$ & $\mathrm{CL}$ & $\mathrm{CL}$ & $\mathrm{C}$ & $\mathrm{C}$ \\
\hline Sanitário-assistencial & $\mathrm{NP}$ & $\mathrm{NP}$ & NP & NP & NP & $\mathrm{C}$ & $\mathrm{C}$ \\
\hline Sócio-cultural-religioso & $\mathrm{NP}$ & NP & NP & NP & NP & $\mathrm{C}$ & $\mathrm{C}$ \\
\hline Desportivo & NP & NP & NP & $\mathrm{NC}$ & $\mathrm{NC}$ & $\mathrm{NC}$ & $\mathrm{C}$ \\
\hline Desportivo de aventura & $\mathrm{NC}$ & $\mathrm{NC}$ & $\mathrm{NC}$ & $\mathrm{NC}$ & $\mathrm{NC}$ & $\mathrm{NC}$ & $\mathrm{NC}$ \\
\hline Acampamento & $\mathrm{NC}$ & $\mathrm{NC}$ & $\mathrm{NC}$ & $\mathrm{NC}$ & $\mathrm{NC}$ & CL* & $\mathrm{CL}^{*}$ \\
\hline Turismo rural & NP & $\mathrm{NC}$ & $\mathrm{NC}$ & $\mathrm{NC}$ & $\mathrm{NC}$ & $\mathrm{CL}^{*}$ & $\mathrm{CL}^{*}$ \\
\hline Trilha Pedestre & $\mathrm{C}$ & $\mathrm{C}$ & $\mathrm{NC}$ & $\mathrm{C}$ & $\mathrm{C}$ & $\mathrm{C}$ & $\mathrm{C}$ \\
\hline Recreativo intensivo & $\mathrm{NC}$ & $\mathrm{NC}$ & $\mathrm{NC}$ & $\mathrm{NC}$ & $\mathrm{NC}$ & $\mathrm{NC}$ & $\mathrm{NC}$ \\
\hline Científico & $\mathrm{C}^{*}$ & $\mathrm{C}^{*}$ & $\mathrm{C}^{*}$ & $\mathrm{C}^{*}$ & $\mathrm{C}^{*}$ & $\mathrm{C}^{*}$ & $\mathrm{C}^{*}$ \\
\hline Informativo & CL* & CL* & $\mathrm{CL}^{*}$ & $\mathrm{CL}^{*}$ & CL* & CL* & CL* \\
\hline Publicitário & NC & $\mathrm{NC}$ & $\mathrm{NC}$ & $\mathrm{NC}$ & $\mathrm{NC}$ & $\mathrm{NC}$ & $\mathrm{CL}^{*}$ \\
\hline Pequeno negócio - mercearias & NP & $\mathrm{NC}$ & $\mathrm{NC}$ & $\mathrm{NC}$ & $\mathrm{NC}$ & CL* & $\mathrm{CL}^{*}$ \\
\hline Comércio ambulante & NP & $\mathrm{NC}$ & $\mathrm{NC}$ & $\mathrm{NC}$ & $\mathrm{NC}$ & $\mathrm{NC}$ & $\mathrm{CL}$ \\
\hline Produção artesanal de produtos tradicionais & NP & $\mathrm{NC}$ & $\mathrm{NC}$ & $\mathrm{NC}$ & $\mathrm{NC}$ & CL* & $\mathrm{CL}^{*}$ \\
\hline
\end{tabular}

Notas: C: Compatível; NC: Não Compatível; CL: Compatível com Limitações; NP: Não Procede. 
Edington et al. (1977), citado Silva (2006, p. 61),

afirma que qualquer alteração do uso do solo constitui uma potencial fonte de perturbação, sendo tarefa do planeamento controlar essas alterações, prevenindo o desequilíbrio. Para tanto, o planeamento deve ter em conta os requisitos locais das novas atividades a implantar e os graus de compatibilidade com os usos envolventes.

Este autor afirma ainda que "a tecnologia pode atenuar algumas limitações, mas existiriam sempre limites mínimos de compatibilidade, considerando a opinião do público como um instrumento para delinear a compatibilidade de funções" (p. 61).

O zonamento do Parque constitui a projeção espacial dos objetivos definidos e a base territorial sobre a qual assentam as disposições normativas. Trata-se de conceber um esquema adequado da distribuição geográfica de usos e atividades a que um determinado território deve submeter-se, assinalando a vocação de cada unidade. Além disso, são regulados aqueles aspetos de capital importância, pelo seu impacte ou consequências sobre o território.

Segundo MADRM (2008), do processo de zonamento foram identificadas e delimitadas três classes de zonas segundo o seu destino e usos gerais: (i) Zona de Uso Moderado (ZUM); (ii) Zona de Uso Tradicional (ZUT); e (iii) Zona de Uso Especial (ZUE), cujas finalidades são (Figura 1):

Figura 1 - Carta de Zonas Básicas

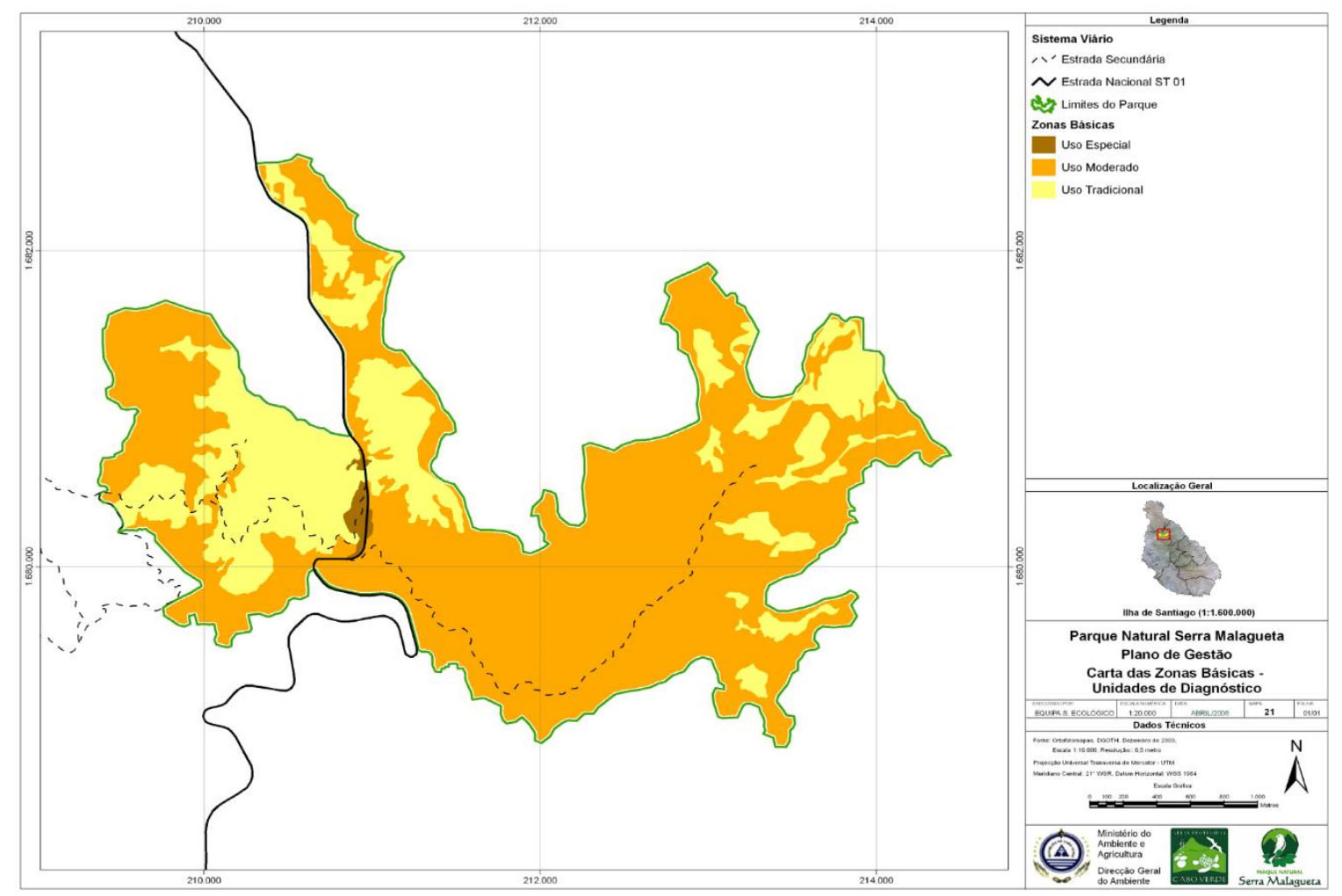

Fonte: Elaboração do autor 
$>\quad$ Zona de uso moderado (ZUM), a finalidade desta zona de uso é a conservação geral dos recursos de forma compatível com a livre circulação e recreio das pessoas, podendo, eventualmente, ser permitida a recolha tradicional de sementes, frutos e outros produtos vegetais, sempre que não afete a flora endémica nem ameace a sobrevivência das plantações naturais.

Zona de Uso Tradicional (ZUT), a finalidade desta zona de uso é permitir as práticas tradicionais de aproveitamento sustentável dos recursos naturais, que podem ser objeto de regulamentação própria.

$>\quad$ Zona de Uso Especial (ZUE), a finalidade desta zona de uso é dar enquadramento aos povoados, casarios, infraestruturas necessárias e diretamente relacionadas com a gestão da área e das visitas, assim como às instalações de interesse público que, por razões técnicas, devem estar situadas dentro dos limites da área protegidas.

De notar que para além de zonas de usos gerais foram identificadas Zonas Específicas, de acordo com as unidades de diagnostico estabelecidas no Plano que correspondem às reações dos ecossistemas face a introdução dos diferentes usos específicos e das atividades. As zonas específicas constituem a base concreta sobre a qual se determinam os diferentes aspetos da gestão do território em relação aos recursos ambientais do Parque, MADRM (2008).

Assim, no âmbito do Parque, delimitaram-se sete zonas específicas segundo seu destino e usos específicos. No Quadro 3, pode-se visualizar a Zona específica Z.3 (Zona arbustiva com prevalência de espécies endémicas), as normas de gestão a que cada "Zona específíca" está sujeita, tanto em termos de uso público como privado, bem assim as respetivas limitações.

A política de gestão ambiental implementada permitiu melhoria na eficácia de gestão do Parque, confirmada pela aplicação da metodologia de avaliação da efetividade de gestão de áreas protegidas, Tracking Tool (Stolton, Sue et al, 2007), comparando a eficácia de gestão avaliada em 2007 com a de 2016, da autoria de Carvalho (2016), classificando-a, de Medianamente satisfatório, enquanto a avaliação de 2007 foi Pouco satisfatório. Ver o Quadro 4.

Quadro 3 - Regulação de usos específico

\begin{tabular}{|l|c|c|c|c|c|c|c|}
\hline \multicolumn{6}{|c|}{ REGULAÇÃO DE USOS ESPECÍFICOS } \\
Z.3 Zona arbustiva com prevalência de espécies endémicas \\
\hline USOS PRIVADOS & C & C $^{*}$ & CL & CL* & NC & NP \\
\hline Residencial-vivenda unifamiliar & & & & & & \\
\hline Agricultura de sequeiro & & & & & & \\
\hline Pecuária estabulada & & & & & & \\
\hline
\end{tabular}




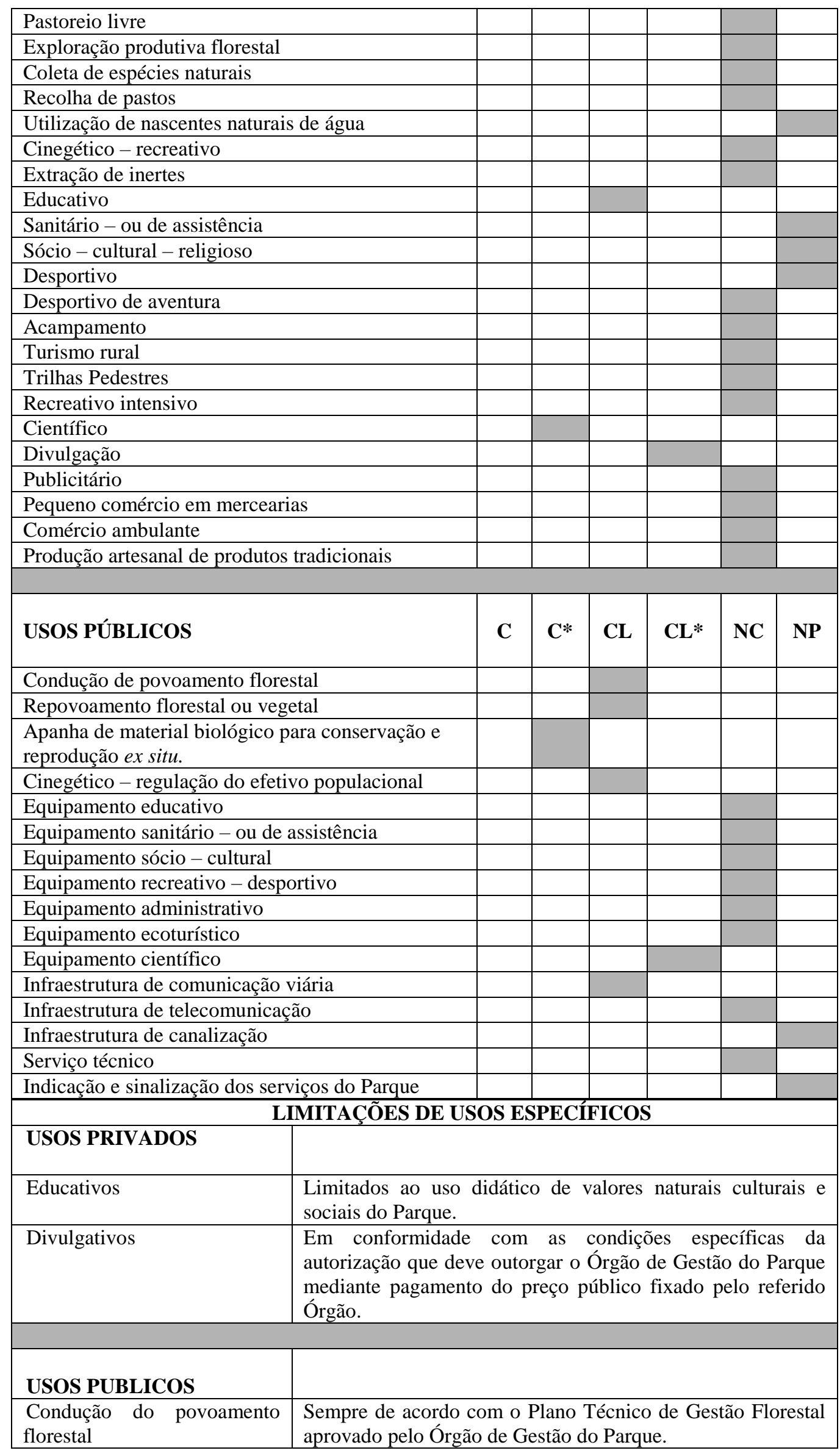




\begin{tabular}{|l|l|}
\hline $\begin{array}{l}\text { Repovoamento florestal ou } \\
\text { vegetal }\end{array}$ & $\begin{array}{l}\text { Em conformidade com o Plano Técnico de Gestão Florestal } \\
\text { aprovado pelo Órgão de Gestão do Parque. }\end{array}$ \\
\hline $\begin{array}{l}\text { Recolha de material biológico } \\
\text { para conservação e e } \\
\text { reprodução } \text { ex situ. }\end{array}$ & $\begin{array}{l}\text { Limitado à recolha de sementes, plantas medicinais e material } \\
\text { biológico em geral, de acordo com as condicionantes } \\
\text { estabelecidas no Decreto-Regulamentar no 7/2002, de 24 de } \\
\text { Dezembro. }\end{array}$ \\
\hline $\begin{array}{l}\text { Cinegético - regulação do } \\
\text { efetivo populacional }\end{array}$ & $\begin{array}{l}\text { Limitado ao controlo populacional do macaco e galinha de } \\
\text { mato, exceto nas áreas onde nidificam as aves protegidas. }\end{array}$ \\
\hline $\begin{array}{l}\text { Equipamento científico } \\
\text { Infraestruturas } \\
\text { comunicação viária }\end{array}$ & $\begin{array}{l}\text { Só quando a instalação autorizada não perturba as condições } \\
\text { de conservação da área onde se pretende fazer a instalação. }\end{array}$ \\
\hline
\end{tabular}

Fonte: Elaboração autor

Quadro 4: Avaliação da Eficácia de Gestão do Parque Natural de Serra da Malagueta

\begin{tabular}{|c|c|c|c|c|c|c|c|c|c|}
\hline \multirow[b]{2}{*}{$\begin{array}{l}\text { Nível: } \\
\leq 35 \% \text { = Insatisfatório } \\
35-50 \% \text { = Pouco satisfatório } \\
51-75 \% \text { = Mediadamente satisfatório } \\
76-89 \% \text { = Satisfatório } \\
\geq 90 \% \text { = Muito satisfatório }\end{array}$} & \multicolumn{9}{|c|}{ ÃMBITOS ANALIZADOS } \\
\hline & 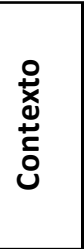 & 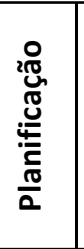 & 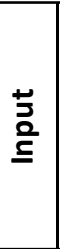 & 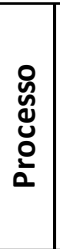 & $\begin{array}{l}\frac{1}{3} \\
\frac{0}{2} \\
0 \\
0\end{array}$ & 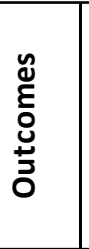 & $\begin{array}{l}\frac{0}{0} \\
\stackrel{0}{0} \\
\frac{1}{0} \\
\frac{0}{\pi} \\
\frac{\pi}{\pi} \\
\stackrel{2}{0}\end{array}$ & 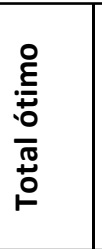 & 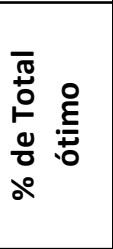 \\
\hline PNSM_2016 & 6 & 23 & 14 & 21 & 2 & 7 & 73 & 104 & 70,19 \\
\hline PNSM_2007 & 6 & 10 & 12 & 18 & 0 & 6 & 52 & 104 & 50,00 \\
\hline
\end{tabular}

Fonte: Elaboração autor

Da análise do Quadro 4, constata-se que a eficácia de gestão em 2016 foi Medianamente satisfatório, enquanto a avaliação de 2007 foi Pouco satisfatório. Esta diferença justifica-se, pois em 2007, embora tivesse havido alguma gestão, o Parque encontrava-se em processo de elaboração do plano de gestão, processo esse que culminou com a aprovação do plano em 2008 e o início da sua implementação no mesmo ano.

Em termos de nível de gestão, o Parque encontra-se na fase "Ativa", pois a maioria dos objetivos de gestão estabelecidos já foram cumpridos, por meio de desenvolvimento de programas de atividades nas áreas de conservação, vigilância, educação, desenvolvimento socioeconómico, divulgação e infraestruturas de uso público que se desenvolvem de forma contínua. Essa afirmação tem por base não só os dados da Quadro 4, mas também a avaliação da eficácia, eficiência e efetividade de gestão dessa área protegida, no âmbito da proposta de tese de doutoramento da autoria de Carvalho (2020, p. 155), que o classifica de "Satisfatório", ao dizer que "Da análise da Tabela 14 e da Figura 5, constata-se que apenas uma área protegida atingiu o nível de qualidade de gestão "Satisfatório", o que significa que nessa área existem condições, em termos de fatores e meios, para o desenvolvimento normal das atividades, tendo em vista a consecução dos objetivos preconizados".

O modelo de gestão adotado, embora assegure a participação das comunidades locais e de outras instituições, através do Conselho Assessor, carece de uma maior descentralização, 
conferindo-lhe autonomia suficiente, flexibilidade e transparência, na gestão dos recursos. Aliás, as experiências acumuladas, não só em Cabo verde, mas também noutras realidades, mostram que "órgãos de controlo ambiental não devem se confundir com órgãos responsáveis pela gestão de unidades de conservação ou mesmo de pesquisa científica” Antunes (2008), citado por Salheb e al. (s/d), p. 15).

Em termos dos impactos socioeconómicos, ecológicos e culturais, segundo o Diretor do Parque, que é também Delegado do Ministério da Agricultura e Ambiente, esse espaço natural protegido tem contribuído para a proteção e conservação dos recursos naturais e ambientais, e isto não só em termos de conservação da flora e fauna endémicas, conservação do solo e água, como também adaptação e mitigação dos efeitos das mudanças climáticas.

Por outro lado, segundo esse Diretor, as estratégias adotadas pelos serviços do Parque em permitir acessos controlados das comunidades locais aos recursos, seja material lenhoso para cozinha como pastos para animais, para além do emprego permanente ou sazonal, tem contribuído para assegurar a satisfação das necessidades económicas a essas comunidades, fazendo com que esse parque, também, atinja os objetivos para que foi criado, nas vertentes socioeconómicas e culturais.

É nosso entendimento que essa área protegida, também, têm tido um papel importante na internacionalização das localidades, ao contribuir para o turismo de base comunitária, uma alternativa inteligente aos males resultantes de uma litoralização excessiva do turismo, em crescimento em Cabo verde, com impactes incomensuráveis, não só nos ecossistemas costeiros, como em termos socioeconómicos e culturais.

\section{CONCLUSÔES}

A compreensão do ambiente e do seu funcionamento têm influências sobre a atitude dos decisores políticos e da sociedade em geral, no que concerne a potenciais impactes da sua decisão política ou das suas atividades no ambiente.

O conhecimento do conceito do ambiente, em termos das suas funcionalidades e vulnerabilidades, é de suma importância, pois isso contribui para uma atitude mais equilibrada do ponto de vista da visão que se possa ter do ambiente, tanto nas perspetivas antropocêntrica, biocêntrica ou ecocêntrica.

A gestão de áreas protegidas é feita adotando estratégias diferenciadas, de acordo com a categoria da cada área. Aliás o próprio nome de uma área protegida é função dos seus objetivos de gestão. 
Tratando-se de um Parque Natural, em que são permitidos o assentamento humano no seu interior e o uso dos recursos naturais de acordo com os princípios de desenvolvimento sustentável, a política de gestão aconselhada deverá ser aquela que assegure, por um lado, diretrizes claras do uso privado/público, através de normativas e, por outro lado, mediação de potenciais conflitos de interesses, não só entre os usuários dos recursos comuns, como entre os interesses económicos privados e conservação dos ecossistemas

A matriz de compatibilidades entre uma atividade em relação a cada unidade de diagnóstico, construído no âmbito do plano de gestão do Parque, MADRM (2008), mostra os limites de capacidade de uso de cada unidade de diagnóstico (capacidade de carga), dando, assim, orientações concretas a potenciais usuários do espaço. O zonamento define um conjunto de classes de uso do Parque, e que são quatro, conforme MAA (2003), traduzidas em zonas básicas, como Zona de Uso Proteção Integral, Zonas de Uso Moderado, Zonas de Uso Tradicional e Zonas de Uso Especial. No caso do Parque Natural de Serra de Malagueta foram identificadas apenas três zonas, como referido acima.

Para além de zonas básicas, também foram identificadas zonas específicas, em número de 7, contendo cada zona, como aliás acontece com as zonas básicas, as condicionantes de uso, e isso na perspetiva do alinhamento dos interesses privados com os da conservação.

Em termos de resultados alcançados, constata-se que a eficácia de gestão em 2016 foi Medianamente Satisfatória, enquanto a avaliação de 2007 foi Pouco Satisfatório. Esta diferença justifica-se: (i) em 2007, embora tivesse havido alguma atividade de gestão, o Parque encontrava-se em processo de elaboração do plano de gestão, processo esse que culminou com a aprovação do plano em 2008 e o início da sua implementação no mesmo ano; e (ii) a política de gestão proativa que o Parque conheceu com a implementação do plano a partir de 2008.

Os resultados alcançados poderiam ser melhorados, por meio do reforço de política de incentivos económicos, se os custos de oportunidade ${ }^{2}$ da conservação fossem internalizados de uma forma mais efetiva nos instrumentos de gestão dessa área protegida.

Relativamente ao modelo de gestão atual do Parque, e da Rede Nacional de Áreas Protegidas de Cabo Verde, recomenda-se que o governo aposte numa maior descentralização,

\footnotetext{
${ }^{2}$ Os custos de oportunidade de uma AP, segundo (Rosário, 2009), têm que ver com os benefícios que a sociedade ou os indivíduos deixam de ter com a não conversão da área, tais como os recursos da flora, fauna, madeireiros e não madeireiros. A restrição ao uso da área por parte da população que vive no interior e/ou na zona de amortecimento da AP, constitui uma perda de bem-estar que deve ser compensada ou ainda, deve existir uma fonte alternativa de rendimento para compensar essa perda.
} 
através da criação de um organismo com autonomia administrativa e financeira, conferindo ao sistema uma maior eficácia, eficiência e efetividade de gestão.

Este trabalho permitiu perceber como é que a abordagem participativa utilizada na territorialização de política de gestão ambiental pública pode contribuir para a sustentabilidade de espaços naturais protegidos.

\section{REFERÊNCIAS}

CARVALHO, M. L. S. Eficácia, eficiência e efetividade de gestão das áreas protegidas de Cabo Verde: uma contribuição para a sustentabilidade da Rede Nacional de áreas protegidas. Tese apresentada ao Programa de Pós-Graduação em Gestão e Políticas Ambientais, como requisito parcial para obtenção do grau de Doutor em Gestão e Políticas ambientais. Cidade da Praia, 2020, 235 p.

CARVALHO, M. L. S. SISTEMA DE ORDENAMENTO DO TERRITÓRIO EM CABO VERDE. Planos Especiais de Ordenamento do Território na Sustentabilidade dos Recursos Naturais: o caso do plano de gestão do Parque Natural de Serra de Malagueta, ilha de Santiago, Cabo Verde, 2016.

Decreto-Lei n. ${ }^{\circ} 49$ (2016, 27 de setembro). Estabelece a estrutura, a organização e as normas de funcionamento do Ministério da Agricultura e Ambiente. Cidade da Praia, 2016.

DIEGUES, A. C. S. O mito moderno da natureza intocada. $2^{a}$ ed. São Paulo: Hucitec. 1998. DUDLEY, N. (Éditeur). Lignes directrices pour l'application des catégories de gestion aux aires protégées. Gland, Suisse : UICN. 2008, X + 96 p.

DULLEY, R. D. Noção de natureza, ambiente, meio ambiente, recursos ambientais e recursos naturais. Agric. São Paulo, São Paulo, v. 51, n. 2, p. 15-26, jul./dez. 2004

FERREIRA, R. C. A evolução da Política Ambiental no mundo. Disponível em: http://www.cenedcursos.com.br/meio-ambiente/politica-ambiental. 2008. Acesso em dezembro de 2016.

FLORIANO, E. P. Políticas de gestão ambiental. 3ed. Santa Maria: UFSM-DCF, 111p., 2007 MATIAS, J. O. Análise Comparativa de Modelos de Gestão de Áreas Protegidas em Países da União Europeia. 2009, 122 p.

Ministério do Ambiente. Desenvolvimento Rural e Recursos Marinhos. (MADRM, 2008). Plano de Gestão do Parque Natural de Serra da Malagueta. Cidade da Praia, Cabo Verde, 2008, $255 \mathrm{p}$.

Ministério do Ambiente e Agricultura. (MAA, 2003). Decreto-Lei $\mathbf{n}^{\mathbf{0}}$ 3/2003, de 24 de Fevereiro, sobre o regime jurídico de espaços naturais. Cabo Verde, 2003.

OOSTERBEEK, L. Direito ambiental ou direito ao ambiente? uma perspectiva de gestão integrada do território. RIDB, Ano 2 (2013), no 12. 14025-14037/http://www.idb-fdul.com/ ISSN: 2182-7567, 2013.

ROSÁRIO, L. T. R. Custo de oportunidade da conservação para populações do entorno de áreas protegidas. In: VIII ENCONTRO DA SOCIEDADE BRASILEIRA DE ECONOMIA ECOLÓGICA, Cuiabá - Mato Grosso, Brasil, 2009.

SALHEB, GLEIDSON JOSÉ MONTEIRO; PERES NETO, HEITOR DE AZEVEDO PICANÇO; OLIVEIRA, IVANCI MAGNO DE; JÚNIOR, MILTON FERREIRA DO 
AMARAL; BOETTGER, RAFAEL JOSÉ CHERFEN DE SOUZA; MONTEIRO, VITÓRIA CHERFEN DE SOUZA. Políticas públicas e meio ambiente: reflexões preliminaries. Revista Planeta Amazônia: Revista Internacional de Direito Ambiental e Políticas Públicas, n. 1, 5 - 26p., 2009.

SILVA, M. T. F. Sustentabilidade ambiental e diferenciação territorial no controlo do desenvolvimento na envolvente a áreas sensíveis - o caso da Ria de Aveiro. Tese de Doutoramento em Ciências Aplicadas ao Ambiente, Universidade de Aveiro, Departamento de Ambiente e Ordenamento, Portugal, 2006, 316p.

SPÍNOLA, C. A. (2013). Parques nacionais, conservação da natureza e inserção social: Uma realidade possível em quatro exemplos de cogestão. Revista Turismo Visão e Ação Eletrônica, Vol. 15 - nº 1 - p. 71-83 / jan-abr., 2013.

STOLTON, SUE; HOCKINGS, MARC; DUDLEY, NIGEL; MACKINNON, KATHY; WHITTEN, TONY; LEVERINGTON, FIONA. Management Effectiveness Tracking Tool. Reporting Progress at Protected Area Sites. WWF International, Second Edition, 2007. 22p. 